\title{
INFLUENCE OF GRAZING MANAGEMENT FACTORS ON HERBAGE AND ANIMAL PRODUCTION FROM LUCERNE PASTURES
}

\author{
K. F. O'CONNOR* \\ Grasslands Division, DSIR, Lincoin
}

\section{PRINCIPLES AND PRACTICE OF LUCERNE MANAGEMENT}

ON sorss with good moisture retention, lucerne pastures at Lincoln have been demonstrated to yield more herbage more reliably than clover-based pastures (O'Connor et al., 1968). On light lands lucerne-based pastures are superior to clover-based pastures (Iversen and Calder, 1956; Flay, 1965; Iversen, 1965). Iversen (1965) demonstrated the beneficial effects to lucerne yield and persistence on light land of "lenient" treatment (involving long spelling duration with short grazing duration) in contrast to "severe" treatment (involving semi-continuous grazing). Iversen (1967) reported similar benefits on a deep soil from such "lenient" treatment in contrast to continuous grazing over the same period from September to May. The work of Vartha (1970) on Wakanui soil at Lincoln has demonstrated that longer spelling duration is beneficial to lucerne in association with grasses where grazing duration was kept short.

These findings accord with the general conclusions of the benefit of long spelling duration in the reviews of Keoghan (1967) and O'Connor (1967) concerning cutting frequency for pure and mixed lucerne stands, Langer (1968) related successful lucerne management to fitting the cutting of grazing regime to the natural growth pattern of the plant, pointing out that normally a new crop of buds on the crown coincides with the appearance of young flowers on existing shoots. Iversen (1967) recommended that lucerne "be grazed boldly and heavily at the early flower stage with from 50 to 200 sheep per acre. The best interval we have found," he said, "is four days' grazing with 36 days of spelling. This requires ten fields and is very easily managed."

Practice may lag behind precept. Blair (1965) found from a survey of farmers that grazing was blamed for a substantial proportion of lucerne deterioration. Stewart

\footnotetext{
* Now Director, Tussock Grasslands and Mountain Lands Institute, Lincoln College.
} 
(1967) in translating an intensive rotational grazing system from a 30 -acre farmlet to a larger scale considered possible compromises between the interests of plant and livestock. An impartial observer of farm practice in Canterbury would probably conclude that the usual compromise was in the supposed interest of stock.

The grazing management studies summarized here were intended to take account of the interests of three components - pasture, animal, manager — in Canterbury farming conditions. All were on established "Wairau" lucerne stands on medium-light soils of Templeton series with small areas of Paparua fine sandy loam.

\section{PRODUCING FAT LAMBS}

Outstanding lamb performances on lucerne at Lincoln (McLean et al., 1962, 1967) were achieved at relatively low grazing pressure for several weeks continuously. Under such management herbage production may be sustained for some time but quality of herbage available steadily deteriorates as selective grazing allows leaves to age and stems to accumulate. Moreover, the higher herbage production potential of lucerne is not likely to be exploited at low stocking rates. In view of these aspects, of the needs of the crop for intermittent rather than continuous grazing, and of the claim (Stewart, 1967) that the crucial element of management of the lucerne farm is the grazing system of ewes and lambs, stocking rates and grazing systems with ewes and lambs were studied. All ewes were intended to lamb about September 1, somewhat earlier than ideal for lucerne on medium-light land.

\section{STOCKING RATE}

From September 16 to December 18 1966, a stocking rate of 7.3 ewes per acre was compared with 10.9 ewes per acre. Each of 120 ewes in six replicates had a single lamb, Border-Leicester cross or Southdown cross, born in the first two weeks of September. Pastures had been

TABLE 1: LIVEWEIGHT GAINS AND DRESSED WEIGHT OF SINGLE LAMBS ON LUCERNE AT TWO STOCKING RATES

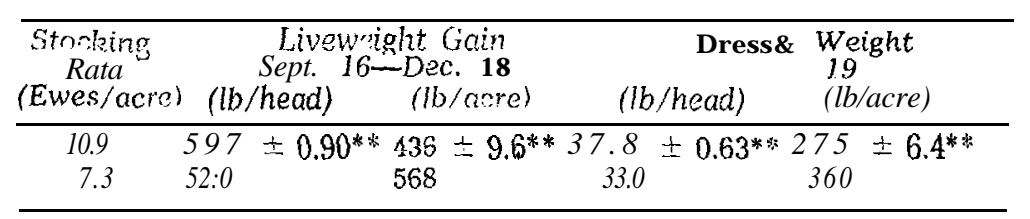


spelled from grazing in July to allow 2,000 lb DM/acre to accumulate by September 16. The grazing system involved about six days' grazing followed by 36 days' spelling. Lamb performance is summarized in Table 1. Although inferior in liveweight gains per head, the higher stocking rate was satisfactory, approximately 100 days from birth being sufficient to reach $33 \mathrm{lb}$ dressed weight.

\section{GraZing SyStem}

On the same pastures in 1967, ewes mated to Romney rams were stocked in April at 11.9 ewes per acre, supplemented with hay at $1 \mathrm{lb}$ and barley at up to $4 \mathrm{oz}$ per animal from May 2 to early July. Access to greenfeed crops was provided during four weeks of mid-winter, the hay ration being continued to early August. The ewes lambed at $108 \%$ and were all transferred to the lucerne pastures during the first week of September. Supplementary feed was terminated and from September 8 two grazing systems were compared in three replicates at 11.9 ewes per acre. Folding or break-grazing involved three days' grazing on each area of about $1 / 6$ acre followed by 39 days' spelling. Periodic stocking rates were 167 ewes per acre. A less intensive rotation of three paddocks involved 14 days' grazing followed by 28 days' spelling. Periodic stocking rates were approximately 36 ewes per acre. Liveweight gains for the last 11 weeks of the twelve-week comparison of grazing systems are presented in Table 2. Break grazing favoured ewes at the expense of lambs, final liveweights of lambs being $58 \mathrm{lb}$ in paddock-grazed mobs and $53.7 \mathrm{lb}$ in break-grazed mobs.

TABLE 2: LIVEWEIGHT GAINS OF EWES AND LAMBS ON LUCERNE UNDER TWO GRAZING SYSTEMS (11.9 ewes and 12.85 lambs per acre - 77 days)

\begin{tabular}{lccccccc}
\hline $\begin{array}{l}\text { Grazing } \\
\text { System }\end{array}$ & Ewes & $\begin{array}{c}\text { Liveweight Gain } \\
\text { (lb/head) } \\
\text { Lambs }\end{array}$ & Ewes & $\begin{array}{c}\text { Liveweight Gain } \\
\text { (lb/acre) } \\
\text { Lambs }\end{array}$ & Total \\
\hline Paddock & 7.1 & \pm & $\mathbf{0 . 2 * *} 34.9 \pm 0.4^{*}$ & $84 \pm \mathbf{2}^{* *}$ & $449 \pm \mathbf{5}^{*} 543$ & $\pm \mathbf{3 . 4 * *}$ \\
Break & 16.2 & 31.2 & & 193 & 401 & 593 & \\
\hline
\end{tabular}

\section{GROWING HOGGETS AND WOOL}

Wether hoggets from the preceding experiment, together with additional similar animals raised on grass/clover pastures, were reassigned into four stocking rate treatments on December 8, 1968. Mean initial liveweight for all groups 
was $62 \mathrm{lb}$. Stocking rates were 7.3/acre (low), 10.9/acre (medium), 14.5/acre (high), and 18.2/acre (very high). Animals were all grazed in a four-paddock rotation involving 14 days' grazing and 42 days' spelling. By late March mean liveweight for low stocking groups had reached $100 \mathrm{lb}$, while that for very high stocking groups was at $70 \mathrm{lb}$. All declined in weight until early May, following severe storms and attacks of pizzle rot.

Winter supplements were begun on April 16 of $1 \mathrm{lb}$ per animal of poor quality hay per day, with barley gradually increased to 8 oz per animal per day. Supplements were maintained at the same per-animal ration until late September, when herbage availability and liveweight gains markedly increased. Mean live weights then ranged from $82 \mathrm{lb}$ at $18.2 \mathrm{per}$ acre to $140 \mathrm{lb}$ at 7.3 per acre. A summary. of liveweight gains in 12 months and wool production in $10 \frac{1}{2}$ months is given in Table 3 .

All animals showed relatively poor growth rates in autumn, but grew rapidly in late spring, especially those at high and very high stocking rates. While all animals gained during winter supplementation, animals at low stocking

TABLE 3:. LIVEWEIGHT GAINS AND FLEECE WEIGHT OF HOGGETS AT DIFFERENT STOCKING RATES ON LUCERNE

\begin{tabular}{|c|c|c|c|c|c|}
\hline $\begin{array}{l}\text { Stocking } \\
\text { Rate } \\
\text { Hgts/acre }\end{array}$ & $\begin{array}{l}\text { Ib Liveweight } \\
\text { per } \\
\text { Hcad Licerno }\end{array}$ & $\begin{array}{l}\text { ain } \\
\text { er } \\
\text { acre }\end{array}$ & $\begin{array}{l}\text { lb } F l \\
\text { per } \\
\text { Head }\end{array}$ & $\begin{array}{c}\text { ce Weight } \\
\text { per } \\
\text { Lucerne }\end{array}$ & acre \\
\hline 18.2 & 49 & & 7.2 & 131 & \\
\hline 14.5 & 61 & & 8.4 & 122 & \\
\hline 10.9 & 71 & & 9.4 & 102 & \\
\hline 7.3 & 87 & & II.3 & 82 & \\
\hline
\end{tabular}

TABLE 4: LEVEL OF PERIODICALLY OFFERED HERBAGE DURING WINTER-EARLY SPRING AT DIFFERENT STOCKING RATES $\times 10^{2} \mathrm{lb}$ dry matter per acre

\begin{tabular}{|c|c|c|c|c|c|}
\hline $\begin{array}{l}\text { Stocking } \\
\text { Rate } \\
\text { Hoggets/ } \\
\text { a cre }\end{array}$ & $\begin{array}{c}\text { Early } \\
\text { Winter }\end{array}$ & $\begin{array}{l}\text { Mid-Late } \\
\text { Winter }\end{array}$ & Early & Spring & Total \\
\hline $\begin{array}{r}18.2 \\
14.5 \\
10.9 \\
7.3\end{array}$ & $\begin{array}{l}4.4 \pm .79 * * \\
5.1 \\
6.2 \\
9.5\end{array}$ & $\begin{array}{l}\mathrm{I} .4 \pm .41 * * \\
1.6 \\
3.1 \\
3.8\end{array}$ & $\begin{array}{r}15.8 \\
16.4 \\
18.1 \\
20.4\end{array}$ & \pm 1.1 n.s. & $\begin{array}{l}21.0 \pm 1.9 * * \\
23.0 \\
27.5 \\
34.2\end{array}$ \\
\hline
\end{tabular}


rate gained more. As all animals were supplemented equally, differences in winter gains may be attributable to lucerne availability. Table 4 summarizes effects of stocking rate on level of periodically offered herbage from May 13 to October 24 (i.e., three cycles of the grazing rotation). High initial grazing pressures at medium to very high stocking rates at each fortnightly change in paddock were quickly aggravated. Although crown bud populations remained high, shoots were kept closely grazed for the last ten days of each grazing period. Only very juvenile shoots were available to grow during early stages of each six-week spell. Analyses of Bailey et al. (1970) and the performance of low stocking rate hoggets in this experiment indicate that lucerne may be a very valuable winter greenfeed. Shortening winter-grazing duration to a few days by more frequent moving of break fences would avert dangers of sustained close shaving by high densities of sheep on dry supplements. Apart from these cool-season effects, no appreciable effects on lucerne herbage production of stocking rate have been discerned.

\section{GRAZING BEHAVIOUR AND PLANT RESPONSE}

Recovery of lucerne was faster and yielded more in 28 days in paddocks grazed for 14 days than in breaks grazed for three days (O'Connor and Vartha, 1968; O'Connor, 1970). This phenomenon was examined more carefully in spring 1969. Lucerne stands in half-acre paddocks were measured for available herbage, stocked at different initial grazing pressures to ensure good utilization of standing crop in $6,12,18$, or 24 days. During grazing, two transects $20 \mathrm{~m} \times 5 \mathrm{~cm}$ were observed every three or six days for the degree of utilization on each stem. Apex removal was rapid, especially in the 6- and 12-day plots. More than $85 \%$ and $70 \%$ respectively of apices were removed in three days on plots being grazed for 6 and 12 days.

From the work of Leach $(1967,1968)$ and our own field studies, we can discern some of the effects of such apex removal. Axillary shoots on stems develop and adventitious shoots emerge from crowns. Removal of apices in spring has been followed by similar crops of basal shoots to those following the removal of two-thirds or more of the herbage canopy. A lag from partial or whole stem removal until shoots appear with opened leaves varies in length from three to ten days. Emerging basal shoots may be initially ignored by stock, but as their leaves unfold they are eaten in preference to older leaves and stems 
LUCERNE MANAGEMENT

\section{TABLE 5: REGROWTH OF LUCERNE IN 36 DAYS FOLLOWING END OF GRAZING PERIODS OF DIFFERENT DURATION IN DIFFERENT SEASONS}

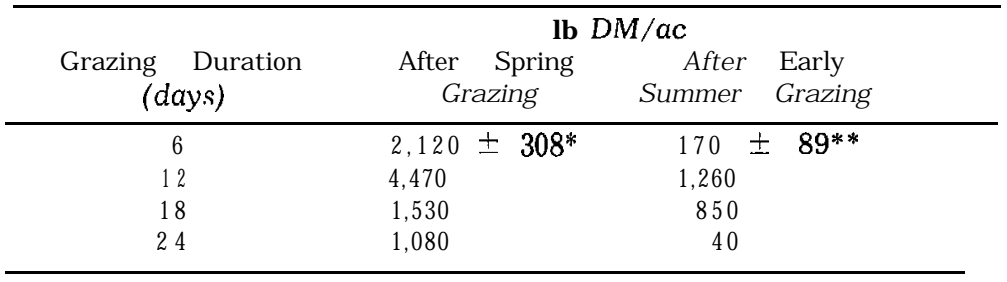

which decline in quality (Bailey et al., 1970). Examples of summary effects of these interactions are shown (Table 5 ) in regrowth following completion of grazings of different durations. The 18-day. and especially 24-day grazings involved serious bottom grazing of induced basal shoots with disastrous results. Six-day grazings, because they were begun later, had later induction of basal shoots and slower initial regrowth especially during incipient drought. On other occasions neither 6-day nor 18-day grazings have been inferior to 12-day grazing in immediate regrowth.

So much for immediate effects. What of longer-term effects? From mid-October 1968, after uniform early spring grazing, a four replicate factorial was established of spelling durations 18, 36, and 54 days and grazing durations 3, 9 and 18 days with additional area kept under semi-continuous grazing, stocking rate being adjusted to moderate grazing pressure.

TAble 6: YIELd AND ROW Density OF LUCERNE PASTURES IN SPRING FOLLOWING DIFFERENT GRAZING SYSTEMS

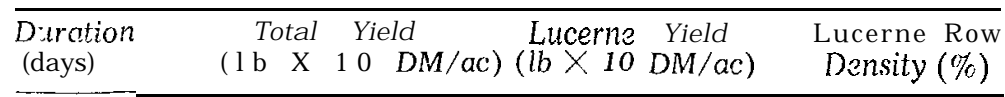

Spelling EFFECTS

\begin{tabular}{lcll}
\hline SPELLING EFFECTS & & & \\
$\mathbf{1 8}$ & $240 \pm 8.7^{* *}$ & $178 \pm 11.0^{* *}$ & $73.3 \pm 1.74^{* * *}$ \\
36 & 308 & 250 & 86.1 \\
54 & 341 & 290 & 89.6
\end{tabular}

\section{Grazing Effects}

\begin{tabular}{|c|c|c|c|}
\hline 3 & $300 \pm 8.7$ n.s. & $238 \pm \mathbf{1 1 . 0}$ n.s. & $81.7 \quad 1.74$ n.s \\
\hline 9 & 286 & 245 & 85.5 \\
\hline 18 & 301 & 244 & 81.0 \\
\hline
\end{tabular}

Semi-CONTINUOUS

GRAZING

$352 \pm 45$

$53 \pm 5.8$

$3.4 \pm .29$ 
Treatments were sustained for five months, paddocks chen spelled during autumn, trimmed off, and spelled until early spring. Herbage production was measured and lucerne density within rows assessed on September 23, 1969. Grazing duration during the previous spring and summer had no effect on 1969 spring production, in contrast with the effect of spelling duration (Table 6). Plots spelled for only 18 days were significantly lower in total yield, yield of lucerne, and stem density. Semi-continuously grazed areas produced high yields of weeds and little lucerne in the subsequent spring.

\section{CONCLUSIONS}

Lucerne management for sheep grazing requires intelligent understanding of plant and animal behaviour. Because lucerne changes in feed quality during spelling (Bailey et al., 1970), one cannot expect a manager to treat it in the interests of the plant alone. Because lucerne changes in feed quality during grazing, one cannot expect animals to treat it except in their own interests. A new compromise must be reached. Lucerne's needs for relatively long spells between grazings (a month or more) should not be compromised. The needs of a farmer and his livestock for some sort of stable existence between moving fences need not be compromised. Further research into the intricacies of lucerne regrowth may refine these recommendations:

(a) A four-paddock rotation system taking about eight weeks to complete the cycle,

(b) Sufficient numbers of the right kind of stock to consume the feed offered, and

(c) Supplementary break fences to shorten grazing duration during critical shortages such as in winter and in summer drought.

So much for practices. In principle I recommend that the manager should be the master of both pasture and stock, not merely their servant.

\section{ACKNOWLEDGEMENTS}

The staff of Grasslands Division, DSIR, Lincoln, all helped in this work. D. J. Parsonson for his management of livestock and Mrs Christine Purdie are to be especially thanked. 


\section{REFERENCES}

Bailey, R. W.; Allison, R. M.; O'Connor, K. F. 1970: Proc N.Z. Grassld Ass., 32: 127.

Blair, I. D., 1965; Cant. Ch. Comm. Agric. Bull., No. 434, 6 pp.

Flay, A. H., 1965: Ashley Dene, 1949-1963, Lincoln Coll. Publ. 3: 31 PP. 8 App.

Iversen, C. E., 1965: Proc. 15th Lincoln Coll. Fmrs' Conf.: 78-83.

1967: In The Lucerne Crop, R. H. M. Langer (ed.), A. H. \& A. W. Reed, Wellington, pp. 129-33.

Iversen, C. E.; Calder, J. W., 1956: Proc. N.Z. Grassld Ass., 18: 78-87. Keoghan, J. M., 1967: In The Lucerne Crop, R. H. M. Langer (ed.), A. H. \& A. W. Reed, Wellington. po. 119-28.

Langer, R. H. M., 1968: Proc. N.Z. Grassld Ass., 30: 12-19.

Lcach, G. J., 1967: In The Lucerne Crop, R. H. M. Langer (ed.), A. H. \& A. W. Reed, Wellington. pp. 15-21.

1968: Aust. J. agric. Res., 19: 517-30.

McLean, J. W.; Thomson, G. G.; Iversen, C. E.; Jagusch, K. T.; Lawson, B. M., 1962: Proc. N.Z. Grassld Ass., 24: 57-68.

McLean, J. W.; Thomson, G. G.; Lawson, B. M., 1967: In The Lucerne Crop, R. H. M. Langer (ed.), A. H. \& A. W. Reed, Wellington. pp. 272-5.

O’Connor, K. F., 1967: In The Lucerne Crop, R. H. M. Langer (ed.),

A. H. \& A. W. Reed, Wellington. pp. 163-76. 1970: Proc. N.Z. ecol. Soc., 18: (In press).

O'Connor, K. F.; Vartha, E. W., 1968: Proc. 21st N.Z. Weed and Pest Control Conf.: 54-9.

O'Connor, K. F.; Vartha, E. W.; Belcher, R. A.; Coulter, J. D., 1968 : Proc. N.Z. G'rassId Ass., 30: 50-63.

Stewart, J. D., 1967: In The Lucerne Crop, R. H. M. Langer (ed.),

A. H. \& A. W. Reed, Wellington. pp. 293-7.

Vartha, E. W., 1970: N.Z. Jl agric. Res. (In press.)

\section{DISCUSSION}

Douglas commented that, at Tara Hills, spring growth was influenced by autumn management, and asked whether the suggestions given for grazing management would apply in that environment. O'Connor stated that the autumn management of plants growing after autumn rains was the same as required in the spring -i.e., two weeks' grazing and six weeks' spelling. In a dry autumn with little growth he recommended a shorter grazing duration- there was a shorter lag between apex movement and bud response. If the plants were flowering, there was virtually no lag and so an even shorter duration was desirable.

As far as winter grazing was concerned, there could be produced valuable green feed, so the grazing duration should again be short and carried out in conjunction with grain feeding-no longer than one week at a time, followed by the six weeks' spell.

Davies asked if oversowing or undersowing with a winter-growing species would be recommended. O'Connor said that he had com. 
pared overdrilled with Tama ryegrass or a cereal with not overdrilled, but had not obtained any significant differences, particularly in animal performance. However, as often occurs in Canterbury, conditions had prevented early enough overdrilling. $\mathrm{He}$ felt an advantage could be obtained if the species was sown early enough and if the area could be irrigated to give the overdrilled material an advantage over the lucerne. In this way it would be possible to obtain an extra $4,000 \mathrm{lb}$ dry matter. The grazing system advocated for the winter-i.e., one week grazing and 6 to 8 weeks spelling - made use of available material, helped in weed control and left the lucerne in excellent condition for the following spring. 